\title{
PENGARUH GAYA KEPEMIMPINAN TRANSFORMATIONAL DAN KOMUNIKASI TERHADAP MOTIVASI DAN DAMPAKNYA PADA KINERJA KARYAWAN PT. XYZ
}

\author{
Andres Dharma Nurhalim
}

Sekolah Tinggi Ilmu Ekonomi Wiyatamandala

andres@wym.ac.id

\begin{abstract}
PT. XYZ is a company engaged in the sale of paper and printing machines which will increase greatly in paper demand is increasing every year. therefore the employee's performance is an important factor in increasing the sales of the company so that it can compete with other competitors. To maintain the necessary motivation employee performance so employees can work maximal.This purpose of study was to analyze the effect of transformational leadership style, communication on the motivation and impact on employee performance PT. XYZ. The population used in this study were all employees of PT. XYZ, Tangerang Cipondoh many as 43 people. The analysis technique used is the path analysis (path analysis).Data obtained from questionnaires distributed to all employees PT. XYZ totaling 43 people to measure transformational leadership style, communication on the motivation and performance of employees by using a Likert scale. From the analysis of the data obtained showed that the Transformational leadership style, communication to motivation and significant influence simultaneously on employee performance.
\end{abstract}

Keywords: transformational leadership, communication, motivation, employees performance.

\section{PENDAHULUAN}

Di tengah kondisi kehidupan era globalisasi ini, perekonomian telah maju dengan sangat pesat dari tahun ke tahun yang diikuti dengan semakin ketatnya persaingan. Semakin tinggi persaingan ,maka setiap perusahaan dituntut untuk menjaga kinerja organisasi agar dapat mempertahankan perusahaannya. Mengingat semakin ketatnya tingkat persaingan antar perusahaan dewasa ini menuntut perusahaan mampu bertahan dan berkompetesi dengan perusahaan lain, salah satu hal yang dapat ditempuh perusahaan ialah mampu bertahan dalam persaingan ketat ini. Peranan sumber daya manusia dalam perusahaan sangatlah penting karena sebagai penggerak utama seluruh kegiatan atau aktivitas perusahaan dalam mencapai tujuannya, baik untuk memperoleh keuntungan maupun untuk mempertahankan kelangsungan hidup 
perusahaan. Berhasil atau tidaknya suatu perusahaan

dalam mempertahankan eksistensi perusahaan dimulai dari manusia itu sendiri dalam mempertahankan perusahaan untuk meningkatkan efektivitas dan efisiensi secara maksimal dalam mencapai kinerja. PT. XYZ adalah perusahaan yang bergerak di bidang usaha kertas selain itu juga perusahaan menjual mesin-mesin percetakan seperti mesin cetak, mesin potong, mesin fotocopy. yang didirikan tahun 2002 di kompleks perkantoran ruko modernland di jalan jendral sudirman Cipondoh Tangerang. PT. XYZ dipercaya menjadi agen tunggal produk jepang dan china di antaranya adalah mesin Offset merk matsuwa dari matsuwa japan, Sakurai Oliver dari Japan, Xarrina dari china. Dalam penelitian yang penulis lakukan, terdapat masalah utama dalam perusahaan ini yaitu karyawan cenderung memiliki kekurangan dalam disiplin kerja. Hal ini di tandai dengan seringnya karyawan datang terlambat, sering bolos yang menunjukkan mereka tidak serius dalam bekerja. Selain itu komunikasi yang terjadi masih kurang berjalan dengan baik sehingga masih terjadi miskomunikasi, khususnya komunikasi pada hubungan antara atasan dengan bawahan hanya sebatas komunikasi dengan media sehingga akibatnya terjadi kesalahan persepsi dan penangkapan informasi yang diberikan. Perumusan Masalah:

1. Apakah ada pengaruh signifikan antara gaya kepemimpinan

transformational terhadap motivasi pada karyawan PT. XYZ?

2. Apakah ada pengaruh komunikasi terhadap motivasi karyawan PT. XYZ ?

3. Apakah ada pengaruh gaya kepemimpinan transformational terhadap kinerja karyawan PT. XYZ

4. Apakah ada pengaruh komunikasi terhadap kinerja karyawan PT. XYZ?

5. Apakah ada pengaruh motivasi terhadap kinerja karyawan PT. XYZ?

6. Apakah ada pengaruh gaya kepemimpinan transformational, komunikasi terhadp motivasi karyawan PT.XYZ?

7. Apakah ada pengaruh gaya kepemimpinan 
transformational,

komunikasi terhadap

motivasi dan dampaknya pada kinerja karyawan PT.

XYZ?

\section{LANDASAN TEORI}

Pengertian Kepemimpinan

\section{Transformational}

Menurut Bass yang dikutip Robbins dan Judge (2007) menjelaskan bahwa Kepemimpinan transformational adalah pemimpin yang memberikan pertimbangan dan rangsangan intelektual yang diindividualkan dan memiliki kharisma. Menurut Bass yang dikutip oleh Yukl (2013) memandang bahwa kepemimpinan transformational adalah suatu keadaan dimana para pengikut dari seorang pemimpin transformational merasa adanya kepercayaan, kekaguman, kesetiaan, dan hormat terhadap pemimpin tersebut, dan mereka termotivasi untuk melakukan lebih dari pada yang awalnya diharapkan mereka. Bass dalam Robbins dan Judge (2007) mengemukakan ada empat komponen kepemimpinan transformational, yaitu:

1. Pengaruh Ideal (Idealized Influence): Pemimpin mempunyai visi dan misi yang jelas menurut persepsi bawahan dapat diwujudkan.dengan dijadikan sebagai panutan, dihormati dan dipercaya,

2. Motivasi yang Inspirasi (Inspirational Motivation): Pemimpin yang inspirasional adalah seorang pemimpin yang bertindak dengan cara memotivasi dan menginspirasi bawahan yang berarti mampu mengomunikasi ekspektasi yang tinggi dari bawahannya, menggunakan simbol-simbol untuk berfokus pada upaya bawahannya dan menyatakan tujuan-tujuan penting secara sederhana.

3. Stimulasi Intelektual (Intellectual Stimulation) : Pemimpin mendorong bawahan untuk lebih kreatif, serta mendorong bawahannya untuk menggunakan pendekatanpendekatan baru yang lebih rasional dalam pengambilan keputusan dan cermat dalam menyelesaikan permasalahan yang ada .

4. Perhatian yang bersifat 


\begin{abstract}
Individual (Individualized
Consideration): $\quad$ Pemimpin

memberikan perihatian pribadi

kepada bawahannya, seperti

memperlakukan mereka sebagai

pribadi yang utuh,

mempertimbangkan kebutuhan

dari bawahannya, serta melatih

dan memberikan saran kepada

bawahannya.
\end{abstract}

\section{Pengertian Komunikasi}

Menurut Onong (2003) menyatakan bahwa komunikasi adalah percakapan yang mengandung persamaan makna dua pihak yang terlibat. Sedangkan menurut Ellen Gufley et al (2006) menyatakan bahwa komunikasi adalah pengiriman informasi dan makna dari satu individu atau kelompok ke individu atau kelompok lainnya. Menurut Onong ada dua dimensi komunikasi yang ada di suatu organisasi antara lain :

1. Komunikasi Internal

Komunikasi internal adalah
proses penyampaian pesan
antara naggota-anggota yang
terjadi untuk kepentingan
organisasi seperti komunikasi
antara pimpinan dan bawahan,
antara sesama bawahan.

Organisasi sebagai kerangka menunjukan adanya pembagian tugas antara orang-orang di dalam organisasi itu dan dapat diklarifikasikan sebagai tenaga pimpinan dan tenanga yang di pimpin. komunikasi internal dapat menjadi dua yaitu pertama, komunikasi vertikal adalah komunikasi dari atas kebawah dan dari bawah ke atas. Komunikasi dari pimpinan kepada bawahan dan dari bawahan kepada pimpinan. Dalam komunikasi vertikal, pemimpin memberikan intruksiintruksi, petunjuk-petunjuk. Pesan-pesan yang dikirim dari manajemen puncak turun ke para bawahan. sedangkan bawahan memberikan laporanlaporan, saran-saran pengaduan dan sebagainya kepada pimpinan. Kedua, komunikasi horizontal yaitu komunikasi antar sesama seperti dari karyawan kepada karyawan, menejer kepada menejer. Pesan dalam komunikasi ini bisa mengalir di bagian yang sama di dalam organisasi atau mengalir di bagian yang sama di dalam 
organisasi atau mengalir antar bagian. Komunikasi lateral ini memperlancar pertukaran pengetahuan, pengalaman, metode, dan masalah. Hal ini membantu organisasi untuk menghindari beberapa masalah dan memecahkan lainnya, serta membangun semangat kerja dan kepuasan kerja

\section{Komunikasi eksternal}

Komunikasi ekternal adalah komunikasi antara pimpinan organisasi dengan khalayak di luar organisasi. Pada organisasi besar,komunikasi ini lebih banyak di lakukan oleh kepala hubungan masyarakat daripada pimpinan sendiri. Dalam komunikasi ekternal terdiri dari atas dua jalur yaitu Pertama, komunikasi dari organisasi kepada khalayak yaitu komunikasi dari organisasi kepada khalayak pada umumnya bersifat informatif, yang di lakukan sedemikian rupa sehingga khalayak merasa memiliki keterlibatan,setidaktidaknya ada hubungan batin. Komunikasi ini dapat melalui berbagai bentuk seperti majalah organisasi, artikel surat kabar atau majalah. Kedua, komunikasi dari khalayak kepada organisasi adalah umpan balik sebagai efek dari kegiatan komunikasi yang dilakukan oleh organisasi.

\section{Pengertian Motivasi}

Menurut Robbins (2006) menyatakan bahwa motivasi adalah proses yang berperan pada insensitas, arah, dan lamanya berlangsung upaya indivudu ke arah pencapaian sasaran. Menurut Hasibuan (2007) menyatakan bahwa motivasi adalah pemberian daya penggerak yang menciptakan kegairahan kerja seseorang agar mereka mau bekerja sama, bekerja efektif dan terintegrasi dengan segala daya upayanya untuk mencapai kepuasan. Maslow mengatakan bahwa kebutuhan manusia dibagi dalam lima tingkatan, tersusun secara hirarkis dan memiliki nilai kepuasan dan tingkat upaya yang berbeda-beda. Kelima tingkat kebutuhan tersebut adalah:

Pertama, kebutuhan fisiologis sering di sebut dengan nama lain yaitu kebutuhan materi antara lain seperti rasa lapar, haus, dan berbagai kebutuhan yang 
bersifat ragawi. Kedua, kebutuhan keamanan perihal keamanan sebagai kebutuhan tidak hanya mengangkat keamanan fisik badan di tempat kerja akan tetapi juga keamanan mental psikologis dalam arti mendapatkan perlakuan yang manusiawi. Kebutuhan Keamanan antara lain seperti keselamatan dan perlindungan terhadap kerugian fisik dan emosional. Ketiga, Kebutuhan Sosial antara lain mencakup kasih sayang, rasa dimiliki, diterima baik dan persahabatan. Kebutuhan tersebut harus di penuhi karena mengingat pentingnya penciptaan dan pemeliharaan iklim kekeluargaan, kebersamaan dan kerja sama dalam kehidupan berorganisasi. Dengan semangat demikian kalaupun terjadi para anggota harus bersaing dengan kekaryaannya, persaingan yang terjadi adalah persaingan yang sehat dan pelaksanaan tugas pekerjaan akan didasarkan pda pendekatan sinergi. Keempat, Kebutuhan Penghargaan antara lain mencakup faktor hormat internal seperti otonomi, prestasi, harga diri. Faktor rasa hormat eksternal yang mencakup status, pengakuan dan perhatian. Kelima, kebutuhan aktualisasi diri berupa pengakuan terhadap kapasitas pengetahuan, keterampilan, dan potensi yang dimilikinya.penting nya kebutuhan ini terpenuhi terlihat pada keinginan yang bersangkutan untuk melaksanakan tugas sekarang dengan lebih baik dan pemuktahiran ilmu serta keterampilan agar sesuai dengan tuntutan organisasi di masa yang akan datang.

\section{Pengertian Kinerja}

Menurut Mathis dan Jackson (2006) kinerja karyawan adalah Apa yang dilakukan atau tidak dilakukan oleh karyawan. Menurut Mathis dan Jackson (2006) kinerja karyawan pada dasarnya untuk mengukur kinerja meliputi elemen sebagai berikut:

1. Kuantintas dari hasil

Pengukuran kuantitas melibatkan perhitungan hasil dari proses atau pelaksanaan kegiatan berkaitan dengan satuan jumlah atau kuantitas yang dihasilkan.

2. Kualitas dari hasil

Pengukuran kualitas berkaitan dengan proses atau hasil mendekati sempurna/ideal dalam memenuhi maksud atau tujuan 
3. Ketepatan waktu dari hasil berkaitan dengan waktu yang diperlukan dalam menyelesaikan aktivitas atau menghasilkan produk

4. Kehadiran berkaitan dengan absensi kehadiran karyawan dalam aktivitas organisasi

5. Kemampuan bekerja sama berkaitan dengan kemampuan dan kemauan untuk bekerja sama dengan pimpinan dan sesama teman kerja.

dengan menggunakan analisis jalur (path analysis). Menurut Sudaryono et al (2013) dalam buku nya yang berjudul pengembangan instrument penelitian pendidikan menyatakan bahwa metode analisis jalur adalah suatu metode yang mengkaji pengaruh efek langsung maupun tidak langsung datri variabel yang di hipotesiskan sebagai akibat pengaruh perlakuan terhadap variable tertentu. model path analysis bertujuan untuk:

1. Penjelasan (explanation) terhadap fenomena yang dipelajari atau permasalahan yang diteliti

2. Prediksi nilai variabel yang terikat (Y) berdasarkan nilai variabel bebas $(\mathrm{X})$, dan prediksi dengan path analysis ini bersifat kualitatif

3. Faktor determinan yaitu penentuan variabel bebas $(\mathrm{X})$ mana yang berpengaruh 
dominan terhadap variabel

terikat (Y), juga dapat

digunakan untuk menelusuri

mekanisme (jalur-jalur)

pengaruh variabel bebas $(\mathrm{X})$

terhadap variabel terikat $(\mathrm{Y})$

4. Pengujian model,

menggunakan theory

trimming, baik untuk uji

reliabilitas (uji keajegan) konsep yang sudah ada

ataupun uji pengembangan

konsep baru.

Kategori seberapa besar pengaruh variabel independen terhadap variabel dependen dalam path analysis dilihat dari nilai koefisien beta akan diuraikan pada tabel dibawah ini:

Tabel 1 Interpretasi Koefisien Jalur Nilai Beta

\begin{tabular}{cc} 
Interval Koefisien jalur & Tingkat Kontribusi \\
$\mathbf{0 , 0 5 - 0 , 0 9}$ & Lemah \\
$\mathbf{0 , 1 0 - 0 , 2 9}$ & Sedang \\
$>\mathbf{0 . 3 0}$ & Kuat \\
\hline
\end{tabular}

Sumber : Riduwan dan Sunarto, 2007

Gambar 1 Model Sub-struktur 1

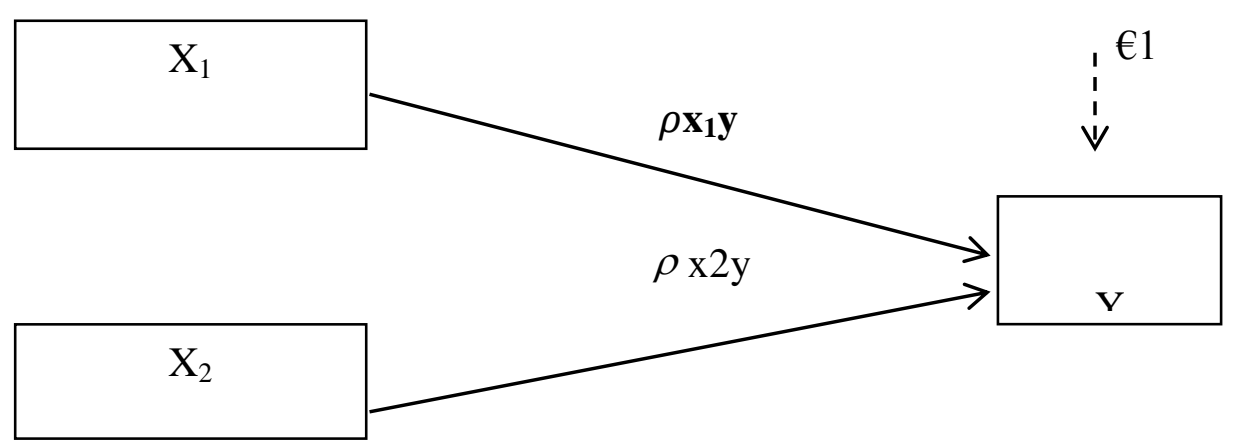

Untuk T-1

Hipotesis :

Ho : Tidak ada pengaruh signifikan antara gaya kepemimpinan
Ha : Ada pengaruh signifikan antara gaya kepemimpinan transformational terhadap motivasi

transformational terhadap motivasi 
Untuk T-2

Hipotesis :

Ho : Tidak ada pengaruh signifikan

antara komunikasi terhadap motivasi
Ha : Ada pengaruh signifikan antara komunikasi terhadap motivasi

Gambar 2 Model Sub-struktur 2

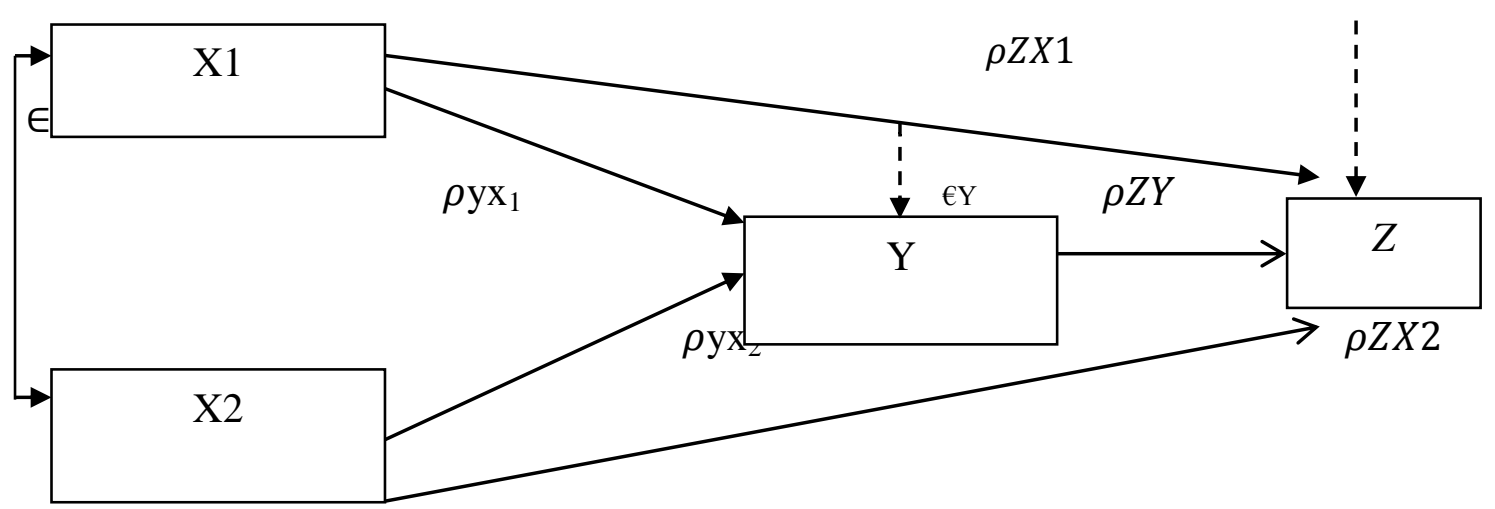

Untuk T-3

Hipotesis :

Ho : Tidak ada pengaruh signifikan antara gaya kepemimpinan transformational terhadap kinerja karyawan.

Ha : Ada pengaruh signifikan antara gaya kepemimpinan transformational terhadap kinerja karyawan.

\section{Untuk T-4}

Hipotesis :

Ho : Tidak ada pengaruh signifikan antara komunikasi terhadap kinerja karyawan.
Ha : Ada pengaruh signifikan antara komunikasi terhadap kinerja karyawan.

\section{Untuk T-5}

Hipotesis :

Ho : Tidak ada pengaruh signifikan antara motivasi terhadap kinerja karyawan.

Ha : Ada pengaruh signifikan antara motivasi terhadap kinerja karyawan.

\section{Untuk T-6}

Hipotesis :

Ho : Tidak ada pengaruh signifikan antara gaya kepemimpinan 
transformational, komunikasi terhadap motivasi.

Ha : Ada pengaruh signifikan antara gaya kepemimpinan transformational, komunikasi terhadap motivasi.

Untuk T-7

Hipotesis :

Ho : Tidak ada pengaruh signifikan antara gaya kepemimpinan

\section{HASIL DAN PEMBAHASAN}

Pada pengujian sub-struktur 1 digunakan untuk mengukur pengaruh dari gaya kepemimpinan transformational terhadap motivasi transformational, komunikasi terhadap motivasi dan dampaknya pada kinerja karyawan.

Ha : Ada pengaruh signifikan antara gaya kepemimpinan transformational, komunikasi terhadap motivasi dan dampaknya pada kinerja karyawan.

pada PT XYZ.. Berikut ini ditampilkan hasil dari pengujian sub-struktur 1 dengan menggunakan bantuan program SPSS.

\section{Hasil Model Sub-Struktur 1}

Tabel 2 Hasil Model Summary ${ }^{\mathrm{b}}$

\begin{tabular}{l|l|lrr} 
Model & \multicolumn{1}{l}{$\mathbf{R}$} & \multicolumn{1}{c}{$\mathbf{R}$} & \multicolumn{1}{c}{$\begin{array}{c}\text { Adjusted R } \\
\text { Square }\end{array}$} & $\begin{array}{l}\text { Std. Error of } \\
\text { Square } \\
\text { the Estimate }\end{array}$ \\
\hline & $.971^{\mathrm{a}}$ & .942 & .939 & 1.56276
\end{tabular}

a. Predictors: (Constant), transformational, komunikasi, motivasi

b. Dependent Variable: motivasi

Berdasarkan tabel di atas nilai R Square sebesar 0,942, yang artinya besarnya pengaruh antara variabel gaya kepemimpinan transformational $\left(\mathrm{X}_{1}\right)$ dan komunikasi $\left(\mathrm{X}_{2}\right)$ mempengaruhi motivasi (Y) sebesar 0,942 (94.2\%) dan sisanya sebesar $\quad 0,058$ dipengaruhi oleh variabel lainnya diluar penelitian ini. Berikut ini besarnya koefisien jalur untuk variabel lain diluar dari penelitian ditentukan dengan persamaan sebagai berikut 


$$
\rho y \varepsilon 1=\sqrt{1-R}=\sqrt{1-0.942}=0,24
$$

Tabel 3 Hasil ANOVA ${ }^{\mathrm{a}}$

$\begin{array}{llcrrrr}\text { Model } & & \begin{array}{c}\text { Sum of } \\ \text { Squares }\end{array} & \text { df } & \begin{array}{c}\text { Mean } \\ \text { Square }\end{array} & \text { F } & \text { Sig. } \\ & \text { Regression } & 1583.358 & 2 & 791.679 & 324.164 & .000^{\mathrm{b}} \\ 1 & \text { Residual } & 97.689 & 40 & 2.442 & & \\ \text { Total } & 1681.046 & 42 & & & \\ \text { a. Dependent Variable: motivasi } & & & & \\ \text { b. Predictors: (Constant), komunikasi, transformational } & \end{array}$

Uji Sig

$\underline{\text { Hipotesis }}$

H0: Tidak ada pengaruh antara gaya kepemimpinan transformational, komunikasi terhadap motivasi $\mathrm{H}_{\mathrm{a}}$ : Ada pengaruh antara gaya kepemimpinan transformational, komunikasi terhadap motivasi
Dasar Pengambilan Keputusan :

Jika angka Sig. $\geq 0,05$, maka $\mathrm{H}_{0}$ diterima dan $\mathrm{H}_{\mathrm{a}}$ ditolak

Jika angka Sig. < 0,05, maka $\mathrm{H}_{0}$ ditolak dan $\mathrm{H}_{\mathrm{a}}$ diterima

Hasil :

Uji Sig. $=0,000<0,05$, maka $\mathrm{H}_{0}$ ditolak dan Ha diterima.

Tabel 4 Hasil Coefficients ${ }^{\mathrm{a}}$

\begin{tabular}{|c|c|c|c|c|c|}
\hline \multirow[t]{2}{*}{ Model } & \multicolumn{2}{|c|}{$\begin{array}{l}\text { Unstandardized } \\
\text { Coefficients }\end{array}$} & \multirow{2}{*}{$\begin{array}{c}\text { Standardized } \\
\text { Coefficients } \\
\text { Beta }\end{array}$} & \multirow[t]{2}{*}{$\mathbf{t}$} & \multirow[t]{2}{*}{ Sig. } \\
\hline & B & Std. Error & & & \\
\hline (Constant) & -3.298 & 1.289 & & -2.559 & .114 \\
\hline transformational & .508 & .103 & .721 & 4.929 & .000 \\
\hline komunikasi & .411 & .235 & .256 & 1.747 & .088 \\
\hline
\end{tabular}


Pengujian Secara Individual antara gaya kepemimpinan

transformational

terhadap motivasi

Hipotesis:

Ho: variabel gaya kepemimpinan transformational tidak berpengaruh secara signifikan terhadap variabel motivasi

Ha: variabel gaya kepemimpinan transformational berpengaruh secara signifikan terhadap varibel motivasi

Dasar Pengambilan Keputusan

$\mathrm{Sig} \geq 0,05$ Ho diterima

Sig $<0,05$ Ho ditolak

Kesimpulan:

Uji $\mathrm{t}=4,929 \geq 1,68$

Uji Sig. $=0,000<0,05$, maka $\mathrm{H}_{0}$ ditolak dan $\mathrm{H} 1$ diterima

Beta $=0,721$
Pengujian Secara individual antara komunikasi terhadap motivasi

Hipotesis:

Ho: Variabel komunikasi tidak berpengaruh secara signifikan terhadap variabel motivasi

Ha: Variabel komunikasi berpengaruh secara signifikan terhadap varibel motivasi

Dasar Pengambilan Keputusan

Sig $\geq 0,05$ Ho diterima

Sig $<0,05$ Ho ditolak

Kesimpulan

Uji $\mathrm{t}=1,747 \geq 1,68$

Uji Sig. $=0,088>0,05$ maka $\mathrm{H}_{0}$ diterima dan $\mathrm{H}_{1}$ ditolak

Beta $=0,256$

Uji Sig

Tabel 5 Hasil Rangkuman Sub-struktur 1

\begin{tabular}{cccccc}
$\begin{array}{c}\text { Pengaruh } \\
\text { Antar }\end{array}$ & $\begin{array}{c}\text { Koefisien } \\
\text { Jalur }\end{array}$ & Sig. & $\begin{array}{c}\text { Pengujian } \\
\text { Hipotesis }\end{array}$ & $\begin{array}{c}\text { Koefisien } \\
\text { Determinasi }\end{array}$ & $\begin{array}{c}\text { Koefisien } \\
\text { Variabel } \\
\text { Lain } \\
(\boldsymbol{\rho} y \varepsilon 1)\end{array}$ \\
$\mathrm{X}_{1}$ terhadap Y & 0,721 & 0,000 & $\mathrm{H}_{1}$ Diterima & $0,942(94,2 \%)$ & 0,240 \\
$\mathrm{X}_{2}$ terhadap Y & 0,526 & 0,088 & $\mathrm{H}_{0}$ Diterima & $0,942(94,2 \%)$ & 0,240 \\
\hline
\end{tabular}

Dengan demikian hasil rangkuman pada model sub-struktur 1 dapat di katakan sebagai berikut: 
Gambar 3 Hasil Sub-struktur 1

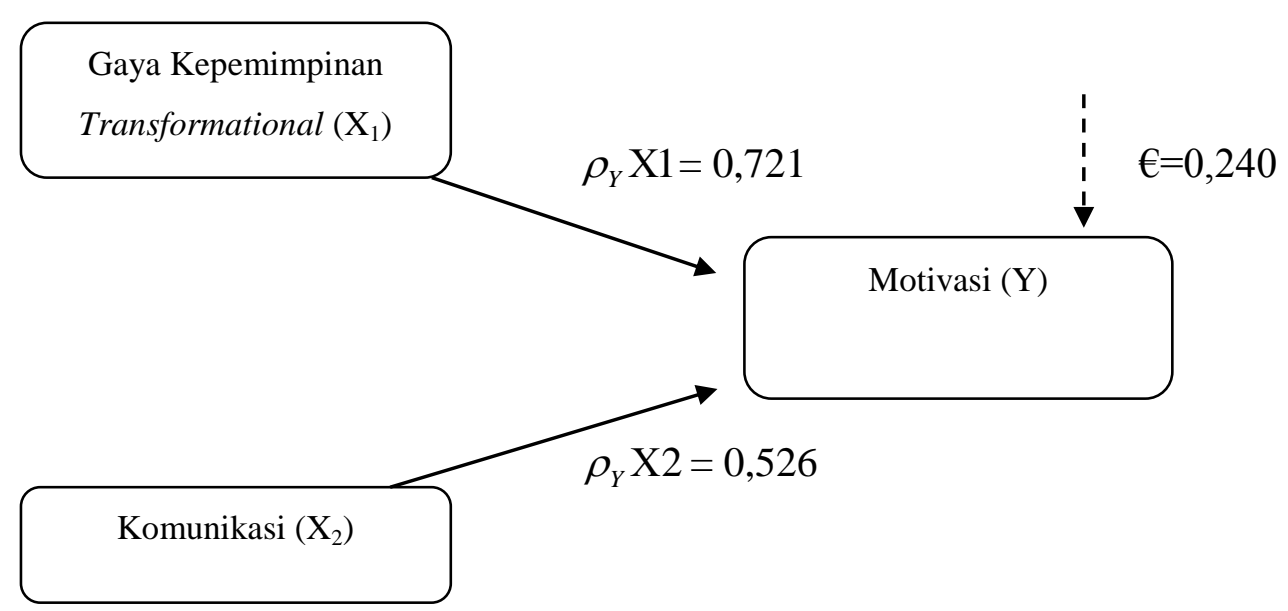

\section{Hasil Model Sub-Struktur 2}

\section{Tabel 6 Model Summary ${ }^{\mathrm{b}}$}

\begin{tabular}{r|rrrr} 
Model & \multicolumn{1}{l}{$\mathbf{R}$} & \multicolumn{1}{c}{$\mathbf{R}$} & \multicolumn{1}{c}{$\begin{array}{c}\text { Adjusted R } \\
\text { Square }\end{array}$} & $\begin{array}{r}\text { Std. Error of } \\
\text { Square } \\
\text { the Estimate }\end{array}$ \\
& $.954^{\mathrm{a}}$ & .910 & .903 & 2.07264
\end{tabular}

a. Predictors: (Constant), transformational, komunikasi, motivasi

b. Dependent Variable: kinerja

Berdasarkan tabel tersebut menunjukan

bahwa nilai R Square sebesar 0,910, yang artinya besarnya pengaruh antara variabel gaya kepemimpinan transformational, komunikasi, motivasi dan dampaknya terhadap kinerja sebesar
0,910 (91\%) dan sisanya sebesar 0,09 (9\%) dipengaruhi oleh variabel lainnya diluar penelitian ini. Berikut ini besarnya koefisien jalur untuk variabel lain diluar dari penelitian ditentukan dengan persamaan sebagai berikut :

$$
\text { py } \varepsilon 1=\sqrt{1-R}=\sqrt{1-0.910}=0,3
$$


Tabel 7 Hasil ANOVA ${ }^{\mathrm{a}}$

\begin{tabular}{|lrrrrr} 
Model & \multicolumn{1}{c}{$\begin{array}{c}\text { Sum of } \\
\text { Squares }\end{array}$} & df & \multicolumn{1}{c}{$\begin{array}{c}\text { Mean } \\
\text { Square }\end{array}$} & \multicolumn{1}{c}{ F } & Sig. \\
Regression & 1691.979 & 3 & 563.993 & 131.288 & $.000^{\mathrm{b}}$ \\
Residual & 167.538 & 39 & 4.296 & & \\
Total & 1859.517 & 42 & & &
\end{tabular}

a. Dependent Variable: kinerja

b. Predictors: (Constant), transformational, komunikasi, motivasi

\section{Uji Sig}

$\underline{\text { Hipotesis }}$

H0: Tidak ada pengaruh antara gaya kepemimpinan transformational, komunikasi terhadap motivasi dan dampak nya pada kinerja karyawan

$\mathrm{H}_{\mathrm{a}}$ : Ada pengaruh antara gaya kepemimpinan transformational, komunikasi terhadap motivasi dan dampak nya pada kinerja karyawan
Dasar Pengambilan Keputusan :

Jika angka Sig. $\geq 0,05$, maka $\mathrm{H}_{0}$ diterima dan $\mathrm{H}_{\mathrm{a}}$ ditolak

Jika angka Sig. $<0,05$, maka $\mathrm{H}_{0}$ ditolak dan $\mathrm{H}_{\mathrm{a}}$ diterima

$\underline{\text { Hasil : }}$

Uji Sig. $=0,000<0,05$, maka $\mathrm{H}_{0}$ ditolak dan $\mathrm{H}_{\mathrm{a}}$ diterima

Tabel 8 Hasil Coefficients ${ }^{\mathrm{a}}$

\begin{tabular}{|c|c|c|c|c|c|}
\hline \multirow[t]{2}{*}{ Model } & \multicolumn{2}{|c|}{$\begin{array}{l}\text { Unstandardized } \\
\text { Coefficients }\end{array}$} & \multirow{2}{*}{$\begin{array}{c}\text { Standardize } \\
\text { d } \\
\text { Coefficients } \\
\text { Beta }\end{array}$} & \multirow[t]{2}{*}{$\mathbf{t}$} & \multirow[t]{2}{*}{ Sig. } \\
\hline & B & Std. Error & & & \\
\hline (Constant) & -.179 & .144 & & -1.097 & .323 \\
\hline transformational & .134 & .210 & .644 & 2.774 & .007 \\
\hline komunikasi & .913 & .124 & .942 & 7.003 & .000 \\
\hline motivasi & .636 & .173 & .604 & 3.031 & .004 \\
\hline a. Dependent Variable: $\mathrm{k}$ & & & & & \\
\hline
\end{tabular}

Pengujian secara individual antara gaya kepemimpinan transformational terhadap kinerja

\section{$\underline{\text { Hipotesis }}$}

Ho: tidak ada pengaruh antara gaya kepemimpinan transformational terhadap kinerja karyawan 
Ha: ada pengaruh antara gaya kepemimpinan transformational terhadap kinerja karyawan

Dasar Pengambilan Keputusan

Sig $\geq 0,05$ Ho diterima Sig $<0,05$ Ho ditolak

\section{$\underline{\text { Kesimpulan }}$}

Uji $\mathrm{t}=2,774 \geq 1,68$

Uji Sig. $=0,007<0,05$, maka $\mathrm{H}_{0}$ ditolak dan $\mathrm{H}_{1}$ diterima

Beta $=0,644$

Pengujian secara individual antara komunikasi terhadap kinerja karyawan

$\underline{\text { Hipotesis }}$

Ho: tidak ada pengaruh antara komunikasi terhadap kinerja karyawan.

Ha: ada pengaruh komunikasi terhadap variabel kinerja karyawan.

Dasar Pengambilan Keputusan

$\mathrm{Sig} \geq 0,05$ Ho diterima $\underline{\text { Kesimpulan }}$

Uji $\mathrm{t}=7.003 \geq 1,68$

Uji Sig. $=0,000<0,05$, maka $\mathrm{H}_{0}$ ditolak dan $\mathrm{H}_{1}$ diterima

Beta $=0,942$

Pengujian Secara Individual antara motivasi terhadap kinerja karyawan

Hipotesis

$H o$ :tidak ada pengaruh antara motivasi terhadap kinerja karyawan

$H a$ : ada pengaruh antara motivasi terhadap kinerja karyawan

Dasar Pengambilan Keputusan

$\mathrm{Sig} \geq 0,05$ Ho diterima $\mathrm{Sig}<0,05 \mathrm{Ho}$ ditolak

$\underline{\text { Kesimpulan }}$

Uji $\mathrm{t}=3,031 \geq 1,68$

Uji Sig. $=0,004<0,05$, maka $\mathrm{H}_{0}$ ditolak dan $\mathrm{H}_{\mathrm{a}}$ diterima

Beta $=0,604$

Sig $<0,05$ Ho ditolak

Gambar 4 Hasil Sub-Struktur 2

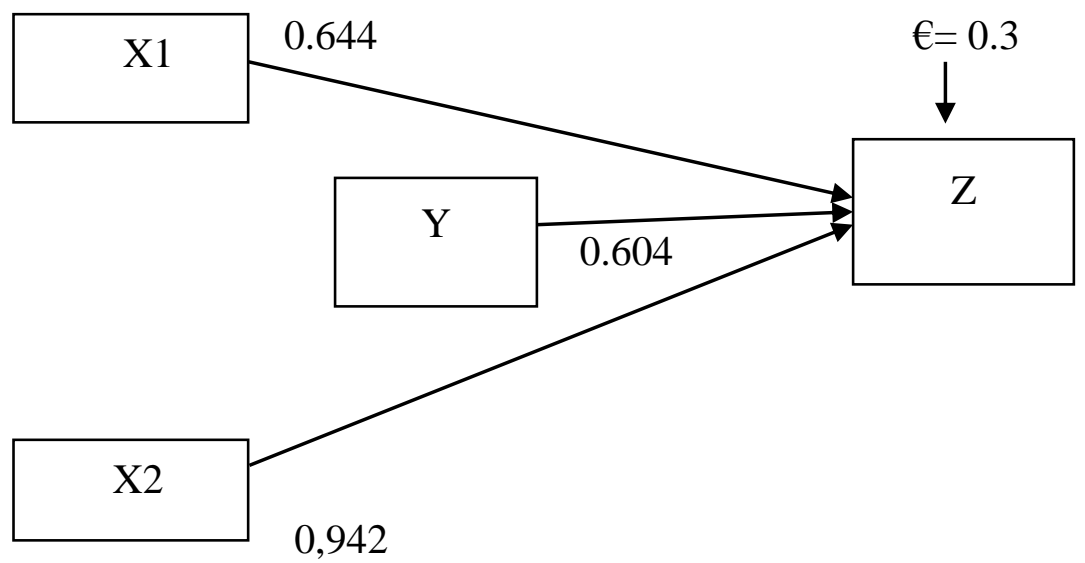


Tabel 9 Hasil Rangkuman Pengujian Sub-Struktur 2

\begin{tabular}{|c|c|c|c|c|c|}
\hline $\begin{array}{c}\text { Pengaruh } \\
\text { Antar } \\
\text { Variabel }\end{array}$ & $\begin{array}{c}\text { Koefisien } \\
\text { Jalur } \\
\text { (Beta) }\end{array}$ & Sig. & $\begin{array}{l}\text { Pengujian } \\
\text { Hipotesis }\end{array}$ & $\begin{array}{c}\text { Koefisien } \\
\text { Determinasi }\end{array}$ & $\begin{array}{c}\text { Koefisien } \\
\text { Variabel } \\
\text { Lain } \\
(\rho z \varepsilon 2)\end{array}$ \\
\hline X1 terhadap Z & 0,644 & 0,007 & $\mathrm{H}_{\mathrm{a}}$ Diterima & & \\
\hline X2 terhadap Z & 0,942 & 0,000 & $\mathrm{H}_{\mathrm{a}}$ Diterima & $0,910(91,0 \%)$ & 0,30 \\
\hline Y terhadap Z & 0,604 & 0,004 & $\mathrm{H}_{\mathrm{a}}$ Diterima & & \\
\hline
\end{tabular}

Gambar 5 Hasil Keseluruhan Model Struktur Path Analysis

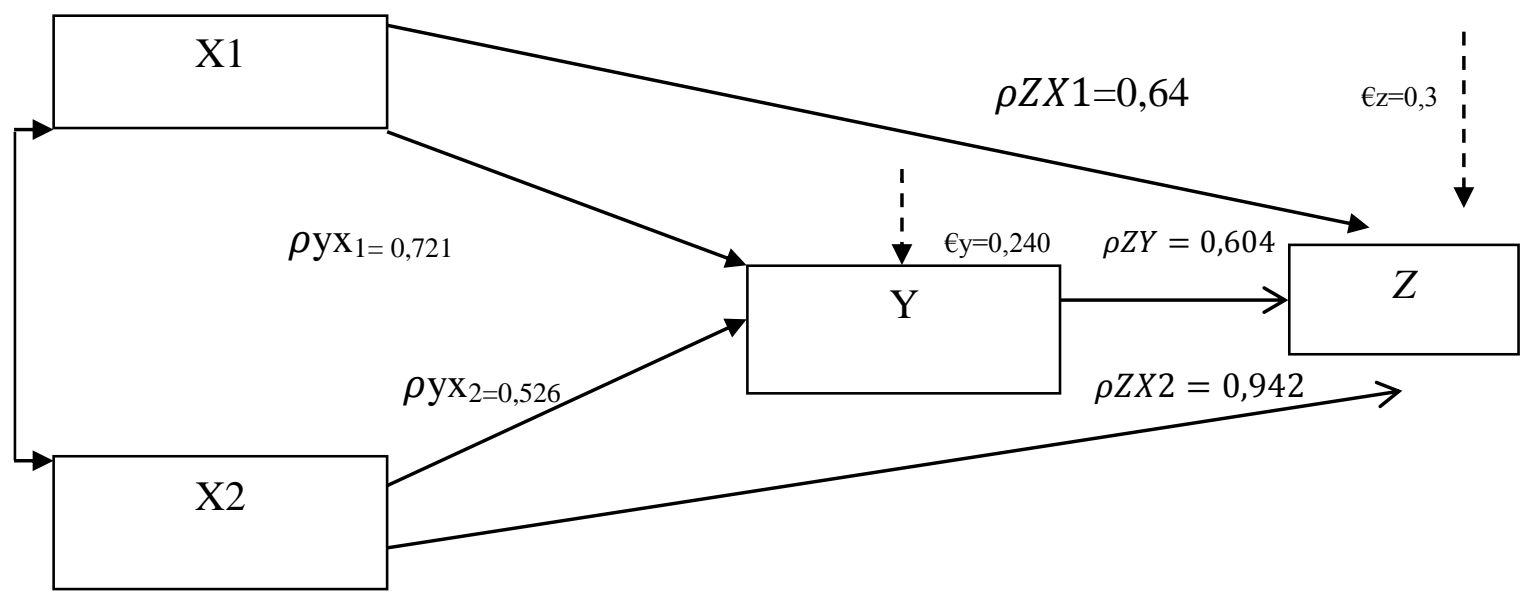

\section{SIMPULAN DAN SARAN}

Berdasarkan pembahasan yang telah di kemukakan sebelumnya maka dapat ditarik kesimpulan dari penelitian ini yaitu untuk model substruktur 1 dapat di katakan bahwa gaya kepemimpinan transformational dan komunikasi memiliki pengaruh terhadap motivasi karyawan Untuk secara individual gaya kepemimpinan transformational memiliki pengaruh terhadap motivasi akan tetapi komunikasi tidak memiliki pengaruh terhadap motivasi, sedangkan untuk model substrukur 2 gaya kepemimpinan transformational, komunikasi terhadap motivasi dan dampaknya pada kinerja memiliki pengaruh baik itu secara parsial maupun secara simultan. Berdasarkan kesimpulan di atas penulis memberikan beberapa saran yang di harapkan dapat bermanfaat dan berguna bagi 
perusahaan. Beberapa saran yang akan di kemukanan adalah PT. XYZ perlu meningkatkan gaya kepemimpinan transformational terutama dalam hal membantu karyawan dalam mendorong keputusan secara rasional dan suasana saling percaya agar kinerja dari karyawan meningkat, dengan cara memberikan kesempatan kepada karyawan untuk memberikan masukan dalam pengambilan keputusan, Keputusan yang di buat hendaknya bermanfaat bagi kedua belah pihak antara atasan maupun bawahan, dan menciptakan suasana rasa saling percaya agar bisa meningkatkan optimis bawahan. PT. XYZ perlu meningkatkan komunikasi internal terutama dengan memberikan karyawan berupa saransaran pengaduan kepada pemimpin. Pimpinan perlu mengetahui tanggapan, atau saran para karyawannya sehingga suatu keputusan atau suatu kebijakann dapat diambil dalam rangka mencapai tujuan yang telah ditetapkan. Selain itu dengan memberikan saran berupa usulan atau masukan, dapat membantu mengatasi kesulitan karyawan. PT.XYZ perlu memperhatikan fisiologis karyawan dalam hal tempat tinggal, dan jaminan keselamatan yaitu perusahaan perlu menyediakan tempat tinggal bagi karyawan paling tidak memberikan pinjaman kepada karyawan untuk mengatasi masalah tempat tinggal. Terjaminnya tempat tinggal bagi karyawan akan memungkinkan para karyawan tersebut untuk bekerja dengan baik sehingga menciptakan motivasi kerja karyawan. Perusahaan perlu memperhatikan jaminan keselamatan kerja dengan cara memberikan ganti rugi kepada karyawan apabila mendapatkan kecelakaan yang menyebabkan karyawan tidak dapat bekerja. Karyawan PT. XYZ perlu meningkatkan kinerja terutama dalam hal mencapai target kerja serta kemampuan dalam menyelesaikan pekerjaan melalui program pelatihan secara berkala agar karyawan dapat melaksanakan tugas dengan kemampuan terbaik dan penting nya sikap kerjasama dengan pemimpin dalam menyelesaikan pekerjaan. 


\section{DAFTAR PUSTAKA}

Ellen Gufley. Et al (2006). Komunikasi Bisnis. Jilid 4. Jakarta, Salemba Empat

Malayu, S.P. Hasibuan, (2007).

Manajemen Sumber Daya

Manusia. Jakarta : Cetakan 9.

PT . Bumi Aksara.

Mathis, Robert L. dan Jackson. (2006).

Manajemen Sumber Daya

Manusia. Jakarta, Salemba

Empat.

Onong, E, U.(2003). Ilmu Komunikasi

Teori dan Praktek. Bandung:

PT. Remaja Rosdakarya

Riduwan dan Sunarto, H.(2007),

Pengantar Statistika Untuk

Penelitian Pendidikan, Social,

Ekonomi, Komunikasi dan

Bisnis. Cetakan 1, Bandung,

Alfabeta.

Robbins, S. P., \& Judge, T. A. (2007).

Organizational Behaviour (ed).

New Jersey: Pearson

International Edition

Robbins,StephenP. (2006).Perilaku

Organisasi. Edisi Indonesia

Jilid 2. Jakarta, Prenhallindo.

Sudaryono, dkk. (2013).

Pengembangan Instrumen

Penelitian Pendidikan.

Yogyakarta: Graha Ilmu.

Yukl, G. (2013). Leadership in

Organization (ed.).Westford:

Pearson, Publishers 